\title{
CRIMINALIDAD ORGANIZADA Y TRÁFICO DE DROGAS ENTRE ESPAÑA Y PORTUGAL
}

\author{
Dr. Karim El Marbouhe El Faqyr
}

Email: $\underline{\text { abogadokmf@gmail.com }}$

\begin{abstract}
RESUMEN: El presente trabajo recoge unas reflexiones generales sobre como se encuentra regulada la criminalidad organizada en Portugal y como se articulan los mecanismos de represión del tráfico de drogas entre España y Portugal mediante el empleo del Tratado Entre España y Portugal para la represión del tráfico ilícito de drogas en el mar, firmado en Lisboa el 2 de marzo de 1998 y como fue empleado por la Audiencia Nacional en el asunto del Buque Eiskos. Además, en este artículo se analiza, desde un punto de vista jurisprudencial las distintas agravantes referentes al delito de salud publica contempladas en el ordenamiento jurídico español.
\end{abstract}

PALABRAS CLAVE: criminalidad organizada, tráfico de drogas, jurisdicción preferente, jurisdicción exclusiva, principio de territorialidad.

\begin{abstract}
This article contains some overall reflections about how organized crime is regulated in Portugal and how the mechanisms of repression of drug trafficking between Spain and Portugal are articulated through the use of the Treaty Between Spain and Portugal for the repression of illicit drug trafficking at sea, signed in Lisbon on March 2, 1998 and as used by the Audiencia Nacional in the matter of the Vessel Eiskos. In addition, this article analyzes, from a jurisprudential point of view, the different aggravating circumstances related to the crime of public health contemplated in the Spanish legal system.
\end{abstract}

KEYWORDS: organized crime, drug trafficking, preferential jurisdiction, exclusive jurisdiction, principle of territoriality. 
SUMARIO: I. Introducción. II. Criminalidad organizada en el ordenamiento jurídico de Portugal. III. Tratado entre España y Portugal para la represión del tráfico ilícito de drogas en el mar. Firmado en Lisboa el 2 de marzo de 1998. IV. Las agravantes aplicables al delito de tráfico de drogas

\section{I.- INTRODUCCIÓN}

En los últimos años en Europa ha habido un aumento significativo del tráfico de estupefacientes y sustancias psicotrópicas, debido a dos grandes factores como pueden ser la crisis económica que atraviesa la euro zona o el aumento de conflictos en los países árabes. Estos dos factores han sido aprovechados por organizaciones criminales asentadas en países del norte de África para introducir en España, Francia e Italia grandes cantidades de hachís sin ser detectadas por las autoridades. La vía utilizada para la introducción de estas sustancias ilegales es el canal del Mediterráneo usando para ello buques mercantes, generalmente antiguos, ya que si son detenidos antes de llegar a su destino no supondría una gran pérdida económica para la organización criminal.

Para paliar este fenómeno los países europeos han desarrollado diversos instrumentos jurídicos y policiales para castigar con dureza a las personas que atentan directamente contra la salud de las personas que conforman nuestra sociedad. En nuestro ordenamiento jurídico existen mecanismos legales para prevenir, perseguir, reprimir y condenar las acciones de las organizaciones dedicadas al narcotráfico. Junto con estos mecanismos internos, España, cuenta con herramientas jurídicas internacionales que son empleadas a diario por los Tribunales españoles en su lucha contra el tráfico internacional. Esta combinación jurídica de ambos ordenamientos se sustenta con nitidez en el artículo 96 de nuestra Constitución Española, el cual defiende que los Tratados Internacionales válidamente celebrados, una vez publicados, formarán parte del ordenamiento interno español.

Ciertamente el empleo de la vía marítima para poder transportar hachís resulta beneficioso para las organizaciones criminales debido a dos cuestiones fundamentales; la primera reside en la posibilidad de transportar en un solo viaje un gran volumen de sustancia psicotrópica mientras que la segunda reside en la dificultad legal que supone dirimir estas cuestiones ya que la aprehensión del hachís en aguas internacionales supone el enfrentamiento de diversas fuentes normativas puesto que no hay una sola jurisdicción punitiva aplicable; siendo esto aprovechado para conseguir la impunidad. 
Las autoridades españolas se enfrentan a diario a grandes operaciones de tráfico debido a la ubicación geográfica de nuestro país. En primer lugar España supone una puerta de entrada rápida hacia Europa; en segundo lugar hay que tener en cuenta la cercanía hacia los países productores y en tercer lugar la Península Ibérica cuenta con miles de kilómetros de costa haciendo más fácil el traslado de estas sustancias ilegales y su trasbordo hacia otros países de la Unión.

Para poder hacer frente a esta problemática los países han ido desarrollando a lo largo de los años diversos instrumentos para luchar contra las mafias que aprovechan los resquicios legales para introducir grandes cantidades de estupefacientes en los países europeos. Cabe recordar que este tráfico de drogas supone una grave amenaza para la salud y el bienestar de la población y además supone un flagrante ataque hacia los pilares económicos, culturales, sociales y políticos de la sociedad. Esta preocupación se traslada también al nacimiento de vínculos entre el tráfico ilícito de drogas y otras actividades delictivas organizadas, como por ejemplo el terrorismo internacional; ya que el narcotráfico puede llegar a ser una gran arteria para la financiación económica de los grupos terroristas.

El nacimiento de estos vínculos delictivos ha generado considerables rendimientos financieros y con ello la aparición de grandes fortunas que permiten a las organizaciones delictivas invadir, contaminar y atacar las estructuras de la administración pública, las actividades comerciales y financieras licitas y sobre todo constituye un ataque en los órganos vitales de la sociedad. Es de vital relevancia destacar que el transporte marítimo es el principal modo de realizar el comercio internacional; ya que este te permite enviar grandes cantidades de mercancía a un coste muy económico. El transporte marítimo podría aglutinar más del $80 \%$ del comercio internacional de mercancías. Desde sus primeros pasos, el transporte marítimo se ha caracterizado por el empleo de grandes embarcaciones cuyo principal objetivo es transportar en un solo viaje la mayor cantidad de mercancía posible; siendo esto conocido por las mafias, el hachís puede ser transportado en buques mercantes, generalmente "viejos", ya que si se produce una detención policial no supondría una gran pérdida económica para la organización. 
Siendo consciente de ello, nuestro ordenamiento jurídico introdujo, en nuestro sistema penal, la agravante de "empleo de buque o aeronaves" para llevar acabo el ilícito penal de tráfico de drogas. El legislador no se ha mantenido aislado de esta problemática internacional, sino que ha actuado endureciendo las penas e introduciendo nuevas modalidades en nuestro Código Penal.

Según el balance de la lucha contra el crimen organizado en España en los años 2013 y siguientes; en nuestro país han sido detectados 497 grupos de crimen organizado; de entre ellos el 52\% han sido organizaciones dedicadas al tráfico de cocaína y de hachís. En el año 2013 solamente en España han sido incautadas 119 embarcaciones que han sido empleadas para el tráfico de drogas. A estos datos habría que añadirles la cantidad de drogas decomisadas en un solo año, que fueron $19.599 \mathrm{~kg}$ de cocaína, $146.708 \mathrm{~kg}$ de hachís y $103 \mathrm{~kg}$ de heroína. Atendiendo a estos datos, el objetivo de la presente Tesis es analizar profundamente los diferentes mecanismos jurídicos y legales tanto nacionales como internacionales y como han sido aplicados en los diferentes casos objeto de estudio. Hay que recordar que en este estudio se va a analizar los casos de mayores alijos de hachís que han azotado España. En virtud de Vigilancia Aduanera y la Agencia Tributaria (AEAT) desde el mes de junio de 2013, las aprehensiones de grandes cantidades de hachís realizadas por la Agencia Tributaria en la 'ruta del Mediterráneo oriental', con un balance de más de 100 toneladas de droga incautadas. Para ello ha sido fundamental la implantación de dispositivos de análisis y control en la ruta comercial del Mediterráneo por las autoridades de Francia, Italia y España, que han derivado en la interceptación de más de una docena de buques que portaban grandes cargas de hachís. Estas operaciones ratifican la importancia de esta nueva ruta abierta para el tráfico de hachís. En el último año y medio, por parte de las autoridades de Italia, Francia y España se ha procedido a la aprehensión de los buques 'Adam', 'Gold Star', 'Luna-S', 'Moon Light', 'Avenir de Safi II', un pesquero egipcio sin nombre, 'Berk Kaptan', 'A la voluntad de Dios', 'Mayak', “Aseel”, “Aberdeen”, “Just Noran”, y el pesquero 'Eiskos' aprehendido al sur de Almería. Con la finalidad de controlar esta nueva ruta del tráfico del hachís que pudiera desviarse a nuestro país, el Departamento de Aduanas e Impuestos Especiales de la Agencia Tributaria ha 
establecido una vigilancia intensiva y permanente sobre la zona, evaluando el riesgo del tráfico marítimo de mercancías e intensificando la colaboración internacional ${ }^{1}$.

Las organizaciones de narcotraficantes son ágiles y flexibles, adaptándose rápidamente a los nuevos escenarios. Los investigadores sospechan que esta ruta estaría siendo empleada por organizaciones situadas en países del norte de África. Transportarían importantes cantidades de hachís en barcos de tipo mercante o pesquero, buques comerciales que efectuarían transportes legales y, a su salida, con una breve parada técnica, reciben importantes cantidades de hachís para su traslado a los países más orientales del Mediterráneo. Estos barcos también pueden ser utilizados como buques nodriza para transbordar el hachís a otras embarcaciones menores, que las alijarían directamente en la costa comunitaria, española, francesa o italiana.

\section{II.- CRIMINALIDAD ORGANIZADA EN EL ORDENAMIENTO JURIDICO DE PORTUGAL}

En el ámbito legal, en Portugal no existe el término específico de "Delincuencia Organizada ". Sin embargo, individuos que pertenecen a redes de crimen, pueden ser castigados bajo la acusación de Asociación Criminal (artículo 299 del Código Penal), Organizaciones Terroristas (artículo 300) o Terrorismo (art. $301^{\circ}$ del C.P.), dependiendo de las circunstancias de las acciones de los detenidos, así como de su consiguiente entendimiento por parte de las autoridades jurídicas. En realidad, la Delincuencia Organizada es mucho más compleja que la "Asociación Criminosa", donde los individuos se organizan para cometer este o aquel delito, como es el caso de las pandillas. Dado que, contrariamente a lo que se piensa, "a la mayoría de los delincuentes no forman parte de grupos estructurados ", grupos, "compuestos principalmente por jóvenes adolescentes del sexo masculino a quienes se juntan algunos jóvenes adultos "2. El hecho de que existen grupos bien organizados en sus actividades criminales, con elevados índices de profesionalismo derivados de la práctica y la consiguiente especialización, no implica necesariamente que estemos ante el del crimen organizado. Por lo tanto, se trata de la modernización criminal, siendo la sofisticación

\footnotetext{
1 Http://www.interior.gob.es/documents/10180/1207668/Bal_CICO_crimen_organizado_2013.pdf/b7cc99 ce-a05f-4389-bd86-1 fa7a9f20694

${ }^{2}$ CUSSON, M. Criminologia. Cruz Quebrada: Casa das Letra, 2006, páginas 12
} 
una mera característica subyacente e indispensable para el éxito del delito. En este caso, sólo estaremos ante una delincuencia organizada cuando el brazo con el que pretendemos combatir toda forma de delincuencia esté paralizado, es decir, cuando los poderes legislativo, ejecutivo o judicial se vuelvan corruptos o "banales" 3 .

La Delincuencia Organizada evoca una definición compleja. Por tratarse de un fenómeno transnacional, nos ceñimos a los requisitos esenciales acordados conjuntamente por la Unión Europea (U.E) y Europol. De acuerdo con el informe producido por estos dos organismos, para que estemos ante un crimen organizado tienen que estar presentes cuatro premisas centrales. Implemente, implica la colaboración de por lo menos tres personas que actúen por uno período de tiempo prolongado o indefinido, perpetradores de graves infracciones penales, con el objetivo primordial de obtener ganancias y / o poder. Por otra parte, pueden estar presentes otras características en este tipo de organizaciones. En particular pueden tener una división específica de "trabajo", operar internacionalmente, utilizar un sistema de disciplina y control, empleando violencia $\mathrm{u}$ otros medios de intimidación para obtener lo que desean. También se puede valer de negocios lícitos para el lavado de dinero o ejercer influencias en diversas áreas, tales como: órganos de comunicación social, política, economía o incluso en la justicia". El delito de "criminalidad organizada" se encuentra regulado en el Capítulo V “de los crímenes contra el orden y la tranquilidad pública”, recogiéndose en la Sección Primera "De los crímenes de antisocialidad peligrosa”, en el artículo 299 del Código Penal portugués 5 .

La definición de Crimen Organizado no es consensual. Mediante un área determinada de conocimiento, de sus prioridades y amplitudes, pueden desarrollarse

\footnotetext{
3 VALENTE, M. Criminalidade Organizada e Criminalidade de Massa. Coimbra, Almedina. 2008, páginas 19-20

${ }^{4}$ NEWBURN, T., Criminology. London, Willan Publishing. 2007, páginas 3-4

${ }^{5}$ CAPÍTULO V Dos crimes contra a ordem e a tranquilidade públicas SECÇÃO I Dos crimes de antisocialidade perigosa Artigo 299 Associação criminosa "1 - Quem promover ou fundar grupo, organização ou associação cuja finalidade ou actividade seja dirigida à prática de crimes é punido com pena de prisão de 1 a 5 anos. 2 - Na mesma pena incorre quem fizer parte de tais grupos, organizações ou associações ou quem os apoiar, nomeadamente fornecendo armas, munições, instrumentos de crime, guarda ou locais para as reuniões, ou qualquer auxílio para que se recrutem novos elementos. 3 - Quem chefiar ou dirigir os grupos, organizações ou associações referidos nos números anteriores é punido com pena de prisão de 2 a 8 anos. 4 - As penas referidas podem ser especialmente atenuadas ou não ter lugar a punição se o agente impedir ou se esforçar seriamente por impedir a continuação dos grupos, organizações ou associações, ou comunicar à autoridade a sua existência de modo a esta poder evitar a prática de crimes."
} 
diferentes perspectivas. Es el caso de la conceptualización del concepto de crimen organizado en enfoque policial, que pone su énfasis en los indicadores criminológicos. En particular: en la planificación, en la preparación de los actos criminales, en los diferentes modos de ejecución y de utilización del producto del delito y, por último, en las relaciones y las ramificaciones entre los actos criminales y los autores. Por otra parte, la perspectiva jurídica lo entiende como un concepto organizativo-asociación, de acuerdo con la durabilidad del fenómeno, la pluralidad de personas y se ha constituido para actividad ilegal; el crimen organizado funciona como una "empresa" restringida que recaba fondos a través de actividades ilícitas. Estas redes o "empresas" atraviesan fronteras terrestres y marítimas, que por su parte capacidad de infiltración en las estructuras jurisdiccionales, políticas y administrativas del Estado, pueden poner en cuestión la propia integridad de éste ${ }^{6}$.

El concepto de criminalidad violenta no es único, sino que va cambiando de Ordenamiento a Ordenamiento. La criminalidad violenta se define en el Código Procesal Penal como "las conductas que deliberadamente se dirigen contra la vida, la integridad física o la libertad de las personas y sean punibles con una pena de prisión de máximo igual o superior a 5 años ". A pesar de que el Código Procesal Penal utiliza un criterio basado en la duración de la pena (más de cinco años de pena de prisión), y habida cuenta de que la pluralidad de crímenes no permitiría trabajar las cuestiones relacionadas con la inmigración, decidimos construir un concepto de criminalidad violenta, no sobre la base de la referencia a la duración de la pena, sino la naturaleza sustantiva de los hechos. Así, nuestra construcción del concepto resulta de la elección de los crímenes por nosotros considerados violentos - por atentar contra la vida humana o la integridad física y la libertad sexual, o implicar la sustracción de bienes por medio de violencia - coincidiendo con los que figuran en las estadísticas de Eurostat4 como violentos "violencia contra las personas", robo - robo por la fuerza o por amenaza de uso de fuerza - y ofensas sexuales - incluyendo la violación y el abuso sexual). Esta elección está también en sintonía con el concepto de criminalidad violenta utilizado por el $\mathrm{FBI}^{7}$. Para todos los crímenes considerados graves y de altísima especialidad y

\footnotetext{
${ }^{6}$ SANTOS CABRAL, J., Uma Incursão pela Polícia. Coimbra, Almedina. 2007, páginas 11-15

${ }^{7}$ GUIA M. J., “Imigrantes e criminalidade violenta em Portugal: Que relaçao?”, O Cabo dos Trabalhos: Revista electrónica dos programas de Mestrado e Doutoramento do CES/FEUC/FLUC. N ${ }^{\circ}$ 4, 2010, páginas 5
} 
peligrosidad, están aprobados por la ley instrumentos jurídicos de investigación criminal más sofisticados para la obtención de la prueba, como es el caso de las búsquedas nocturnas en domicilios, intersección y grabación de comunicaciones, agente infiltrado y registro de voz y imagen, siendo este medio más utilizado para los crímenes económico-financieros considerados, innumerables veces, típicos de la actividad delictiva organizada y del propio terrorismo ${ }^{8}$. De todas las características subyacentes a la criminalidad, tal vez la más importante para la sociedad en general, sea la violencia empleada por los criminales en la conquista de sus objetivos. Esto porque, la criminalidad violenta es aquella que más contribuye al sentimiento de inseguridad en una sociedad 9 .

De acuerdo con el informe de Europol de 2013, más del 70\% de los grupos los delincuentes están compuestos por miembros de múltiples nacionalidades y más del $30 \%$ se dedican a varios tipos de crimen. En el 25\% de los casos estos grupos estaban subdivididos en grupos homogéneos con una nacionalidad dominante. En un $20 \%$ se trataba de grupos de composición mixta, con dos nacionalidades principales; y, por último, con el $25 \%$ surgieron los grupos puramente heterogéneos con más de dos nacionalidades. Por lo que se refiere a las nacionalidades, los grupos no pertenecientes a la Unión Europea están constituidos por individuos de América Latina, países de la antigua Unión Soviética, Afganistán, Pakistán, países del Este Asiático y del Magreb. En cuanto a la unión de miembros procedentes de la Unión Europea y de países terceros, las combinaciones más patentes son: oriundas de américa latina y portugueses; letones y ruso; y del Magreb, aliados con portugueses y / o españoles ${ }^{10}$.

La forma de organización de una red traduce su intento criminal, su sofisticación, experiencia y competencia van paralelamente a los desafíos y oportunidades en la sociedad moderna ${ }^{11}$. Las redes criminales son estructuradas por dos modelos distintos. Las que poseen una estructura vertical son operadas por diferentes niveles de "oficiales", remontando jerarquías clásicas. Las de estructura horizontal son

\footnotetext{
8 VALENTE, M. Criminalidade Organizada e Criminalidade de Massa. Coimbra, Almedina. 2008, páginas 22

9 Reno, J., \& Fisher R. C., \& Robinson L., \& Brennan, N., \& Gist, N. Addressing Community Gang Problems: A Practical Guide. Washington, DC: Bureau of Justice Assistance.1998, páginas 23-24

10 Serviço de Informações de Segurança: Crime Organizado Transnacional. Disponível em http://www.sis.pt/ccorganizada.html. Documento consultado em 2 de Junho de 2012.

${ }^{11}$ CUSSON, M. Criminologia. Cruz Quebrada: Casa das Letra.2006, páginas 2-6
} 
menos rígidas y no tienen una jerarquía permanente. No obstante, estos son los dos modelos más patentes, existen otras formas de organización, donde los grupos pueden adoptar características de estos dos modelos, no adoptar ninguna, o regirse por otras premisas peculiares, de acuerdo con sus designios. De señalar que, el concepto de jerarquía criminal es distinto de jerarquía organizacional tradicional, incluso cuando las redes criminales poseen una estricta división de tareas y de especialización. Al evitar las estructuras organizativas formales y adoptar una organización jerárquica más flexible, los grupos criminales refuerzan su capacidad para ocultar sus actividades y perseguir sus objetivos ilícitos. Muchas veces adoptan un enfoque compartido de liderazgo, traduciéndose en un cambio relevante cualitativa, que enfatiza, entre otros aspectos, el esfuerzo del grupo, la complementariedad de competencias y de mayor colaboración entre los líderes. La forma más común del liderazgo compartido prevé dos líderes en el mando, pero hay grupos con equipos de liderazgo más grandes. Curiosamente, las redes criminales cuyo núcleo del liderazgo es más amplio presentan una relación relativamente más estable y cohesiva entre sus miembros que las que tienen una jerarquía más estricta, con sólo un líder ${ }^{12}$.

La evolución de los grupos del crimen organizado resultó en diversos cambios, en su forma de operar, bien en su propia estructura. Estas mutaciones llevaron a un aumento de su movilidad criminal; a un mejor funcionamiento de la organización criminal; la creación de células y operaciones paralelas en varios Estados miembros; a la concentración en los países menos afectados y la explotación de las diferencias de legislación a través de las jurisdicciones nacionales. Es cierto que los grupos que se dedican al crimen violento y organizado difieren en el nivel de conocimiento y competencia que son capaces de emplear en sus actividades criminales. Sin embargo, todos tienen por objeto máximo de oportunidades para alcanzar objetivos comunes para la ganancia financiera, mutuo, siendo necesario para ello, operar más allá de las fronteras para garantizar determinados servicios o productos específicos, como es el caso del tráfico de drogas. Ahora bien, tal cooperación que ocurre tanto a nivel nacional

12 Serviço de Informações de Segurança: Crime Organizado Transnacional. Disponível em http://www.sis.pt/ccorganizada.html. Documento consultado em 2 de Junho de 2012. 
como internacional, acaba por conducir inevitablemente a una mayor profesionalización del crimen organizado ${ }^{13}$.

\section{III.- TRATADO ENTRE ESPAÑA Y PORTUGAL PARA LA REPRESIÓN DEL TRÁFICO ILÍCITO DE DROGAS EN EL MAR. FIRMADO EN LISBOA EL 2 \\ DE MARZO DE 1998}

Teniendo como único objetivo repeler la entrada en sus territorios de sustancias nocivas para la salud, España y Portugal hacen suyas las palabras recogidas en el apartado noveno del artículo 17 de la Convención de Naciones Unidas de 1988, el cual faculta a los Estados firmantes a concertar acuerdos o arreglos bilaterales y regionales para llevar a la práctica las disposiciones del presente artículo o hacerlas más eficaces. Estos dos países son vulnerables en la introducción de sustancias ilegales en sus territorios puesto que comparten una única base territorial, sobre la cual aparece un gran cinturón de costas marítimas que dificultan en cierta manera el control del tráfico ilícito por mar. Con la finalidad de tener un mayor control punitivo sobre las bandas criminales dedicadas al tráfico de drogas y sustancias psicotrópicas, España y el Reino de Portugal, lanzaron una ofensiva bilateral, con el propósito de afianzar la cooperación otorgada por la Convención de Naciones Unidas de 1988. Este nuevo instrumento jurídico fue denominado "Tratado entre España y la República portuguesa para la represión del tráfico ilícito de drogas en el mar".

Comienza este Tratado delimitando la competencia de ambos países bajo un respeto profundo de la Soberanía nacional que ostenta cada uno en su territorio. Para evitar intromisiones en la jurisdicción y competencia interna, este Tratado delimita que cada Parte ejercerá jurisdicción exclusiva en relación con los hechos realizados en sus aguas territoriales, zonas o puertos francos, incluidos los hechos que se hubieren iniciado o se deberían consumar en el otro Estado ${ }^{14}$. La clave de esta delimitación reside en el respeto a la normativa interna de cada país, mediante la cual otorga jurisdicción a los Tribunales para conocer de los hechos delictivos que ocurran en su territorio nacional o que se hayan preparado en el mismo, aunque la finalización del acto delictivo apunte al territorio del otro Estado Parte.

\footnotetext{
13 VASCONCELOS, Ricardo Manuel Costa. Criminalidade organizada em Portugal: um estudo exploratório. Tesis Doctoral, 2013. Páginas 76-79

${ }^{14}$ Artículo 3 Del Tratado entre España y la República portuguesa para la represión del tráfico ilícito de drogas en el mar.
} 
Este respeto a la Soberanía nacional se ve plasmado también en el apartado segundo del artículo 3 del Tratado, el cual expone que:

"En relación con los hechos realizados fuera de las aguas territoriales de uno de los dos Estados, tendrá jurisdicción preferente el Estado del pabellón del buque a bordo del cual o a través del cual se hubieren realizado los dichos hechos".

En definitiva, este artículo 3 no viene sino a reforzar el principio de territorialidad recogido en nuestra Ley Orgánica del Poder Judicial en su apartado primero del artículo 23 de nuestra LOPJ establece que:

“En el orden penal corresponderá a la jurisdicción española el conocimiento de las causas por delitos y faltas cometidos en territorio español o cometidos a bordo de buques o aeronaves españoles, sin perjuicio de lo previsto en los tratados internacionales en los que España sea parte.”

Sin embargo, este Tratado hispano-luso, introduce un concepto nuevo a la hora de dirimir las cuestiones de competencia que puedan surgir; este concepto es el de "jurisdicción preferente" y se encuentra definido en el artículo primero apartado "b" como:

"b) «Jurisdicción preferente» significa que cuando exista concurrencia de jurisdicciones de ambos Estados Parte, en relación a una infracción pertinente, el Estado del pabellón tiene derecho a ejercer su jurisdicción con exclusión de la jurisdicción del otro Estado Parte."

Este concepto de "jurisdicción preferente" fue empleado por el Ministerio Público de Portugal en el asunto del Buque "Eiskos" para poder reclamar la competencia y jurisdicción de los tribunales lusos para conocer y enjuiciar la tripulación del precitado buque ${ }^{15}$.

\footnotetext{
${ }^{15}$ Vid. PROCEDIMIENTO DILIGENCIAS PREVIAS- PROCEDIMIENTO ABREVIADO 000098/2014 DEL JUZGADO CENTRAL DE INSTRUCCIÓN NUMERO 3 DE MADRID. NIG 280792722014 0002698. ANTECEDENTES DE HECHO: El día 27 de Octubre de 2014 el buque EISKOS habría partido desde la dársena de Bouzas, en el Puerto de Vigo (Pontevedra, ESPAÑA), trasladándose posteriormente hasta un punto próximo a la costa de Marruecos, donde un barco procedente de dicho país realizaría el trasbordo de una gran cantidad de fardos conteniendo HACHIS. Con fecha 31 de Octubre de $\underline{2014}$ se remite a la Subdirección General de Operaciones de Vigilancia Aduanera, solicitud para el abordaje del barco pesquero denominado EISKOS por encontrarse en su interior una gran cantidad de sustancias estupefacientes, en concreto HACHIS. Que el pasado día 23 de Noviembre de 2014 cuando el pesquero EISKOS se encontraba en aguas internacionales a 28 millas de Cabo de Gata (Almería), se
} 


\section{a. Intervención De Las Partes}

Este Tratado acuna la forma de intervenir reflejada en la Convención de las naciones Unidas de 1988, es decir, para que una de las Partes pueda intervenir sobre un buque del otro Estado que se encuentre fuera de sus aguas territoriales, deben existir sospechas fundadas y razonadas de que el buque objeto de medidas se encuentra realizando algún hecho tipificado como ilícito por el ordenamiento penal.

Una vez que las sospechas adquieren forma de certeza, cada Parte reconoce a la otra un derecho de representación; esta representación se traduce en que los navíos oficiales podrán perseguir, parar y abordar el buque sospechoso, examinar documentos, interrogar a la tripulación y demás personas que se encuentren a bordo. Si se produce la confirmación de que el buque ha sido empleado para un acto delictivo, se procederá a la aprehensión de la droga, a la detención de las personas presuntamente responsables y a la conducción del buque hasta el puerto más próximo más adecuado para su inmovilización ${ }^{16}$. Al igual que en la Convención, esta cooperación o derecho de representación presenta unos requisitos y estos vienen recogidos en los artículos quinto y sexto del Tratado, encuadrándose en los siguientes:

1. Obligación de comunicar al Estado del pabellón la existencia de sospechas fundadas.

2. El Estado requerido, es decir el país de abanderamiento, tendrá que enviar respuesta a tal requerimiento en un plazo que no exceda de cuatro horas siguientes a la recepción de la solicitud. En dicha respuesta, el Estado requerido tendrá que enviar toda la información disponible del buque en cuestión.

produjo su asalto por el Servicio de Vigilancia Aduanera. Dicha detención se produjo como consecuencia de la solicitud de colaboración internacional emitida por las Autoridades Portuguesas, al objeto de proceder a la localización y abordaje de la citada embarcación pesquera. La excelentísima Audiencia Nacional basa la cesión de jurisdicción a las autoridades portuguesas debido que la investigación se realizó en Portugal, que allí están las fuente de prueba fundamentales y que en aquel país tiene su centro principal de operaciones en Europa la organización criminal investigada, siendo de aquella nacionalidad sus dirigentes; así como en la petición del Departamento Central de Investigación de Portugal en donde se pretende ejercer su jurisdicción preferencial en base al Tratado entre el Reino de España y la República Portuguesa para la represión del tráfico ilegal de drogas en el mar.

${ }^{16}$ Artículo 4 Del Tratado entre España y la República portuguesa para la represión del tráfico ilícito de drogas en el mar. 
3. Si la intervención no fuera inminente, se notificará la intención de intervenir al Estado requerido para que en el plazo de cuatro horas autorice o deniegue dicha intervención.

4. En el caso de que no fuese posible obtener respuesta a la solicitud en el plazo estipulado, se podrán desarrollar las medidas de intervención, debiendo el comandante del navío oficial comunicar su actuación a la autoridad competente del Estado de abanderamiento del buque.

5. Toda intervención que deberá realizarse en alta mar deberá no comprometer la seguridad de las personas, del buque y de la carga, así como no perjudicar los intereses comerciales de otros.

6. Los detenidos en la operación tendrán los derechos inherentes a toda persona nacional, respetándose sus derechos fundamentales a ser asistido por un intérprete y a disfrutar de la asistencia de un Abogado.

7. El capitán del buque tendrá el derecho de comunicar dicha detención a sus autoridades y a mantener contacto con su Cónsul.

8. Si la intervención se realizará y esas sospechas resultasen falsas, el Estado interviniente podrá ser responsable de los daños y perjuicios, salvo que hubiere intervenido a instancias del Estado del pabellón.

\section{b. Invocación De La Jurisdicción Preferente}

Este Tratado introduce un nuevo concepto para otorgar la competencia al Estado de abanderamiento del buque y es el de "jurisdicción preferente". Como ya se ha dicho anteriormente este concepto viene definido, en apartado b del artículo primero del Tratado hispano-luso, como:

"b) «Jurisdicción preferente» significa que cuando exista concurrencia de jurisdicciones de ambos Estados Parte, en relación a una infracción pertinente, el Estado del pabellón tiene derecho a ejercer su jurisdicción con exclusión de la jurisdicción del otro Estado Parte." 
Se podría entender que esta jurisdicción preferente es automática, sin embargo, a tenor de lo defendido en el artículo $7^{17}$ del propio Tratado, se vislumbra que el Estado requerido, es decir, el país de abanderamiento del buque, puede renunciar a ejercer tal jurisdicción a favor del Estado interviniente.

La forma de proceder con respecto a la jurisdicción preferente es la siguiente:

1. El Estado interviniente, una vez hechas las primeras diligencias informará al Estado del pabellón de los posibles hechos delictivos cometidos.

2. El Estado de abanderamiento del buque tiene un plazo de catorce días para comunicar al Estado interviniente si ejerce o no su jurisdicción preferente.

3. Si transcurrido el plazo el Estado requerido no manifestará su voluntad, se entenderá que renuncia al ejercicio de su jurisdicción.

4. Si el Estado del pabellón del buque retenido decidiese ejercer su jurisdicción preferente, se le devolverá inmediatamente el buque, la carga y el material probatorio escoltándose el buque hasta el límite de las aguas territoriales del Estado interviniente.

5. En lo referente a los supuestos autores del tipo delictivo, se puede manifestar que:

\footnotetext{
${ }^{17}$ Artículo 7 Del Tratado entre España y la República portuguesa para la represión del tráfico ilícito de drogas en el mar. Artículo 7 Renuncia a la jurisdicción 1. Cada Estado tiene jurisdicción preferente sobre sus buques, pudiendo renunciar a ella en favor del Estado interviniente. 2. El Estado interviniente, después de efectuar las primeras diligencias, transmitirá al Estado del pabellón un resumen del material probatorio recogido, relativo a todas las infracciones pertinentes cometidas, anticipándolo, si fuere posible, por telecopia, debiendo el Estado del pabellón responder en el plazo de catorce días acerca de si ejercerá su jurisdicción o si renuncia a la misma, pudiendo pedir una información complementaria, si lo estimare necesario. 3. Transcurrido el plazo referido en el apartado anterior sin que haya sido comunicada decisión alguna, se presumirá que el Estado del pabellón renuncia al ejercicio de su jurisdicción. 4. Si el Estado del pabellón decide ejercer su jurisdicción preferente, se le devolverá inmediatamente el buque, la carga y el material probatorio, escoltándose el buque hasta el límite de las aguas territoriales del Estado interviniente. 5. La entrega de las personas detenidas no exigirá un procedimiento formal de extradición, siendo suficiente un mandato judicial individualizado de detención o equivalente, respetándose los principios fundamentales del ordenamiento jurídico de cada parte. El Estado interviniente certificará el período de detención sufrido. 6. En lugar de la entrega, el Estado del pabellón podrá pedir la libertad inmediata de las personas detenidas o del buque, decretándose ésta inmediatamente por el Estado interviniente. 7. El período de privación de libertad sufrido en uno de los Estados Parte será descontado de la pena que fuere impuesta por el Estado que ha ejercido su jurisdicción.
} 
a No será necesario un procedimiento formal para su extradición, sino simplemente un mandamiento judicial individualizado de detención o equivalente.

b Si el Estado del pabellón decidiese otorgar la libertad de las personas detenidas, el Estado interviniente tendrá la obligación de respetar dicha decisión y decretará su inmediata liberación.

c El periodo de privación de libertad sufrido en uno de los Estados Parte será descontado de la pena que fuere impuesta por el Estado que ejerza su jurisdicción.

Las autoridades estatales encargadas de desplegar toda la maquinaria jurídica recogida en este Tratado serán los Ministerios de Justicia. En caso de especial urgencia las autoridades del estado interviniente podrán dirigirse directamente al Ministerio de justicia del Estado del pabellón o a las autoridades competentes indicaras por este Ministerio $^{18}$.

\section{c. Principio De Territorialidad dentro de la Jurisdicción española}

El apartado primero del artículo 23 de nuestra LOPJ establece que:

"En el orden penal corresponderá a la jurisdicción española el conocimiento de las causas por delitos y faltas cometidos en territorio español o cometidos a bordo de buques o aeronaves españoles, sin perjuicio de lo previsto en los tratados internacionales en los que España sea parte."

En esta primera aproximación se puede observar que el legislador abarca todos los delitos cometidos en territorio español y también aquellos delitos cometidos a bordo de buques o aeronaves españoles; en este segundo aspecto al hablar sobre buques hay que recordar el tipo de abanderamiento del mismo, porque tal y como se recoge en el precitado apartado, para que España tenga la jurisdicción total y absoluta sobre el buque este tiene que tener bandera española. En el caso de que no la tuviese ya entraría en juego el ordenamiento jurídico internacional que será estudiado en los siguientes capítulos.

\footnotetext{
${ }^{18}$ Artículo 8 Del Tratado entre España y la República portuguesa para la represión del tráfico ilícito de drogas en el mar.
} 
Al ubicar la acción penal en el Mar, además de la Ley de Enjuiciamiento Criminal y la LOPJ, resulta necesaria la aplicación del Derecho del Mar, existiendo también en este caso un ordenamiento marítimo nacional y otro internacional. E1 sistema central del Derecho del Mar se ubica en Convención de las Naciones Unidas sobre el Derecho del Mar, hecha en Montego Bay en el año1982. Con este instrumento jurídico se intenta clarificar toda la problemática internacional y sobre todo sirve como anclaje entre el ordenamiento interno y la soberanía del estado español en el mar.

Según esta Convención la soberanía de España se extienda más allá de su territorio y de sus aguas interiores y, en el caso del Estado archipelágico, de sus aguas archipelágicas, a la franja de mar adyacente designada con el nombre de mar territorial.

Esta soberanía se extiende al espacio aéreo sobre el mar territorial, así como al lecho y al subsuelo de ese mar $^{19}$. Las costas españolas, conforman lo que se conoce como "mar territorial" y tienen una anchura que no excede de 12 millas marinas medidas a partir de líneas de base determinadas de conformidad con esta Convención ${ }^{20}$.

Sin embargo, aunque el estado ejerza su jurisdicción en el llamado mar territorial, la potestad penal no deberá ejercerse contra un buque extranjero, que navegue dentro de las 12 millas que conforman la soberanía nacional, para detener a ninguna persona o realizar ninguna investigación en relación con un delito cometido a bordo de dicho buque durante su paso salvo que se den las siguientes circunstancias ${ }^{21}$ :

a Cuando el delito tenga consecuencias en el Estado ribereño;

b Cuando el delito sea de tal naturaleza que pueda perturbar la paz del país o el buen orden en el mar territorial.

c Cuando el capitán del buque o un agente diplomático o funcionario consular del Estado del pabellón hayan solicitado la asistencia de las autoridades locales.

d Cuando tales medidas sean necesarias para la represión del tráfico ilícito de estupefacientes o de sustancias sicotrópicas.

\footnotetext{
${ }^{19}$ Artículo 2 de la Convención de Montego Bay "Régimen jurídico del mar territorial, del espacio aéreo situado sobre el mar territorial y de su lecho y subsuelo"

${ }^{20}$ Artículo 3 de la Convención de Montego Bay

${ }^{21}$ Artículo 27 de la Convención de Montego Bay "Jurisdicción penal a bordo de un buque extranjero"
} 
Para proceder a la detención o investigación de un buque extranjero que navegue por el mar territorial es necesario, antes de tomar cualquier medida, poner en conocimiento de esta acción a las autoridades, a un agente diplomático o funcionario consular del Estado del pabellón y facilitará el contacto entre tal agente o funcionario y la tripulación del buque. En caso de urgencia, la notificación podrá hacerse mientras se tomen las medidas ${ }^{22}$.

Conforme vayamos alejándonos de la base física territorial que compone el Estado, estamos entrando en la jurisdicción internacional y por lo tanto sometemos los casos de aprehensiones de buques con carga de drogas a diversas interpretaciones jurídicas. Si salimos de la zona del "mar territorial" nos encontraríamos con la "zona contigua". Esta zona no podrá extenderse más allá de las 24 millas marinas contadas desde las líneas de base a partir de las cuales se mide la anchura del mar territorial ${ }^{23}$. La jurisdicción en esta parte del mar se limita a dos medidas de fiscalización, siendo estas:

a Prevenir las infracciones de sus leyes y reglamentos aduaneros, fiscales, de inmigración o sanitarios que se cometan en su territorio o en su mar territorial

b Sancionar las infracciones de esas leyes y reglamentos cometidas en su territorio o en su mar territorial.

Profundizando y adentrándonos en alta mar, al pasar la "zona contigua" estaríamos en la "zona económica exclusiva", esta zona viene no se extenderá más allá de las 200 millas marinas contadas desde las líneas de base a partir de las cuales se mide la anchura del mar territorial. La zona económica exclusiva viene descrita en los artículos $55^{24}, 56^{25}$ y $57^{26}$ de la Convención del mar, los cuales exponen que la zona

\footnotetext{
${ }^{22}$ Artículo 27.3 de la Convención de Montego Bay "Jurisdicción penal a bordo de un buque extranjero"

${ }^{23}$ Artículo 33.2 de la Convención de Montego Bay Sección 4 Zona Contigua.

${ }^{24}$ Artículo 55 de la Convención de Montego Bay. Régimen jurídico específico de la zona económica exclusiva La zona económica exclusiva es un área situada más allá del mar territorial y adyacente a éste, sujeta al régimen jurídico específico establecido en esta Parte, de acuerdo con el cual los derechos y la jurisdicción del Estado ribereño y los derechos y libertades de los demás Estados se rigen por las disposiciones pertinentes de esta Convención.

${ }^{25}$ Artículo 56 Convención de Montego Bay. Derechos, jurisdicción y deberes del Estado ribereño en la zona económica exclusiva 1. En la zona económica exclusiva, el Estado ribereño tiene: a) Derechos de soberanía para los fines de exploración y explotación, conservación y administración de los recursos naturales, tanto vivos como no vivos, de las aguas suprayacentes al lecho y del lecho y el subsuelo del mar, y con respecto a otras actividades con miras a la exploración y explotación económicas de la zona, tal como la producción de energía derivada del agua, de las corrientes y de los vientos; b) Jurisdicción,
} 
económica exclusiva es un área situada más allá del mar territorial y adyacente a éste, sujeta al régimen jurídico específico de acuerdo con el derecho internacional, y lo más importante de todo es que el Estado ribereño tiene derecho a explotar y conservar los recursos naturales de la zona exclusiva, a realizar investigaciones y a proteger y conservar el estado marino.

La última zona que nos podríamos encontrar en este dibujo marítimo, es la "alta mar”. Esta zona marítima se caracteriza por tener un régimen jurídico más flexible siendo este el principio de la libertad de navegación. En este caso los buques navegarán bajo el pabellón de un solo Estado y, salvo en los casos excepcionales previstos de modo expreso en los tratados internacionales o en esta Convención, estarán sometidos, en la alta mar, a la jurisdicción exclusiva de dicho Estado. Siendo conscientes de la problemática que supone el tráfico internacional de drogas y sustancias psicotrópicas y la facilidad con la que actúan los criminales en las zonas marítimas, esta Convención del Mar asentó las bases para la lucha y represión de este tipo delictivo; fijándose las mismas en su artículo 108, recogiéndose de la siguiente manera:

1. Todos los Estados cooperarán para reprimir el tráfico ilícito de estupefacientes y sustancias sicotrópicas realizado por buques en la alta mar en violación de las convenciones internacionales.

2. Todo Estado que tenga motivos razonables para creer que un buque que enarbola su pabellón se dedica al tráfico ilícito de estupefacientes o sustancias sicotrópicas podrá solicitar la cooperación de otros Estados para poner fin a tal tráfico.

Este artículo sirve como pieza de unión del entramado jurídico internacional que componen la primera línea defensiva en la lucha contra el narcotráfico, siendo siempre

con arreglo a las disposiciones pertinentes de esta Convención, con respecto a: i) El establecimiento y la utilización de islas artificiales, instalaciones y estructuras; ii) La investigación científica marina; iii) La protección y preservación del medio marino; c) Otros derechos y deberes previstos en esta convención. 2. En el ejercicio de sus derechos y en el cumplimiento de sus deberes en la zona económica exclusiva en virtud de esta Convención, el Estado ribereño tendrá debidamente en cuenta los derechos y deberes de los demás Estados y actuará de manera compatible con las disposiciones de esta Convención. 3. Los derechos enunciados en este artículo con respecto al lecho del mar y su subsuelo se ejercerán de conformidad con la Parte VI.

26 Artículo 57 de la Convención de Montego Bay: expone que la zona económica exclusiva no se extenderá más allá de 200 millas marinas contadas desde las líneas de base a partir de las cuales se mide la anchura del mar territorial. 
necesario ponerlo en armonía con el resto de la normativa reguladora del ordenamiento nacional.

\section{IV.- LAS AGRAVANTES APLICABLES AL DELITO DE TRAFICO DE DROGAS}

Para enfrentarse a este "tráfico internacional" el tipo básico no tiene la suficiente entidad para hacer frente a esta problemática quedándose infinitamente alejado de su capacidad punitiva. Es de vital relevancia destacar que el transporte marítimo es el principal modo de realizar el comercio internacional; ya que este te permite enviar grandes cantidades de mercancía a un coste muy económico. Desde sus primeros pasos, el transporte marítimo se ha caracterizado por el empleo de grandes embarcaciones cuyo principal objetivo es transportar en un solo viaje la mayor cantidad de mercancía posible; siendo esto conocido por las mafias, el hachís puede ser transportado en buques mercantes, generalmente "viejos", ya que si se produce una detención policial no supondría una gran pérdida económica para la organización.

El legislador no se ha mantenido aislado de esta problemática internacional, sino que ha actuado endureciendo las penas e introduciendo nuevas modalidades en nuestro Código Penal. Siendo consciente de ello; nuestro legislador, ha optado por la introducción de ciertas agravantes que en cierta medida sean capaces de luchar contra estos actos delictivos. Estas agravantes han sido asentadas en dos grandes escalones bien diferenciados, los artículos 369 y 370 del Código Penal. El artículo 369 C.P. establece que:

"1. Se impondrán las penas superiores en grado a las señaladas en el artículo anterior y multa del tanto al cuádruplo cuando concurran algunas de las siguientes circunstancias:

1. ${ }^{a}$ El culpable fuere autoridad, funcionario público, facultativo, trabajador social, docente o educador y obrase en el ejercicio de su cargo, profesión u oficio.

2. ${ }^{a} \quad$ El culpable participare en otras actividades organizadas o cuya ejecución se vea facilitada por la comisión del delito.

3. ${ }^{a}$ Los hechos fueren realizados en establecimientos abiertos al público por los responsables o empleados de los mismos. 
4. ${ }^{a}$ Las sustancias a que se refiere el artículo anterior se faciliten a menores de 18 años, a disminuidos psíquicos o a personas sometidas a tratamiento de deshabituación o rehabilitación.

$5{ }^{a} \quad$ Fuere de notoria importancia la cantidad de las citadas sustancias objeto de las conductas a que se refiere el artículo anterior.

6. ${ }^{a} \quad$ Las referidas sustancias se adulteren, manipulen o mezclen entre sí o con otras, incrementando el posible daño a la salud.

7. ${ }^{a} \quad$ Las conductas descritas en el artículo anterior tengan lugar en centros docentes, en centros, establecimientos o unidades militares, en establecimientos penitenciarios o en centros de deshabituación o rehabilitación, o en sus proximidades.

8. ${ }^{a} \quad$ El culpable empleare violencia o exhibiere o hiciese uso de armas para cometer el hecho."

En este artículo en su apartado $5^{\circ}$ ya podemos visualizar la primera agravante aplicable al tráfico a gran escala, "la notoria importancia", asentando en una primera instancia los puntos básicos delictivos e introduciendo posteriormente las claves que endurecen la penalidad de estos actos. Para ello nuestro Código Penal hace un barrido de las circunstancias personales y materiales que envuelven al caso.

Continuando con su lucha contra el tráfico internacional de estupefacientes, los legisladores introducen una nueva cualificación especial para el caso de que el supuesto autor perteneciese a una organización delictiva; exponiéndose esta cualificación en el artículo 369 bis del C.P., reflejándose de la siguiente manera:

"Cuando los hechos descritos en el artículo 368 se hayan realizado por quienes pertenecieren a una organización delictiva, se impondrán las penas de prisión de nueve a doce años y multa del tanto al cuádruplo del valor de la droga si se tratara de sustancias y productos que causen grave daño a la salud y de prisión de cuatro años y seis meses a diez años y la misma multa en los demás casos. A los jefes, encargados o administradores de la organización se les impondrán las penas superiores en grado a las señaladas en el párrafo primero."

No siendo suficiente para abarcar el delito de narcotráfico internacional la Ley Orgánica 5/2010, de 22 de junio, por la que se modifica la Ley Orgánica 10/1995, de 23 
de noviembre, del Código Penal, introduce una cualificación de segundo grado que permite elevar las penas del artículo 368 en uno o dos grados; quedando recogida en el artículo 370 de la siguiente manera:

"Se impondrá la pena superior en uno o dos grados a la señalada en el artículo 368 cuando:

1. ${ }^{\circ}$ Se utilice a menores de 18 años o a disminuidos psíquicos para cometer estos delitos.

2. ${ }^{\circ}$ Se trate de los jefes, administradores o encargados de las organizaciones a que se refiere la circunstancia $2^{a}$ del apartado 1 del artículo 369.

\section{Las conductas descritas en el artículo 368 fuesen de extrema gravedad.}

Se consideran de extrema gravedad los casos en que la cantidad de las sustancias a que se refiere el artículo 368 excediere notablemente de la considerada como de notoria importancia, o se hayan utilizado buques, embarcaciones o aeronaves como medio de transporte especifico, o se hayan llevado a cabo las conductas indicadas simulando operaciones de comercio internacional entre empresas, o se trate de redes internacionales dedicadas a este tipo de actividades, o cuando concurrieren tres o más de las circunstancias previstas en el artículo 369.1."

Llegados a este punto es importante referenciar que para entender el delito de narcotráfico internacional, es necesario relacionar el tipo básico recogido en el artículo 368 del Códice penal junto con las agravantes expuestas en los artículos 369, 369 bis y 370 del mismo cuerpo legal.

\section{a. Notoria Importancia}

Esta primera agravante se encuentra recogida en el apartado $5^{\circ}$ del artículo 369 del Código Penal, y su interpretación ha sido ambigua y siempre ha generado grandes discrepancias a la hora de considerar qué se entiende por "cantidad de notoria importancia". Para dar respuesta a este enigma jurídico el Tribunal Supremo ha reaccionado de forma activa procediendo a unificar criterios; celebrándose el 19 de octubre de 2001 Pleno no jurisdiccional de la Sala Segunda, asentando los criterios necesarios para la aplicación del subtipo de "notoria importancia". La conclusión alcanzada consiste en que "la agravante especifica de cantidad de notoria importancia de 
drogas tóxicas, estupefacientes o sustancias psicotrópicas, prevista en el apartado 3 del artículo 369 del Código Penal, se determina a partir de las quinientas dosis de Toxicología de 18 de octubre de 2001”27, teniendo en cuenta, para su concreción exclusivamente la sustancia base o tóxica, reducida a pureza, con la salvedad del hachís y sus derivados.

En su Sentencia de 06 de Noviembre de 2001, nuestro más alto Tribunal expuso las razones por las que se opta por esta cantidad de "quinientas dosis"; razonándose de la siguiente manera: "tratándose de tráfico de estupefacientes, parece razonable partir de las cifras que cuantifiquen el consumo diario estimado de un consumidor medio y a partir de ahí fijar la notoria importancia en atención a las cantidades de droga que permita establecer un mercado importante (cincuenta consumidores) durante un periodo relevante de tiempo (diez días). Se obtiene así la cifra de quinientas dosis de consumo diario, aplicable a todas las drogas...”. A la luz de las consideraciones realizadas por este Pleno, se considera cantidad de notoria importancia las dosis equivalentes a los 2500 gramos de hachís, 750 gramos de cocaína.

\section{b. Pertenencia A Grupo Criminal}

La cualificación de notoria importancia se ha ido reforzando para encuadrar el delito de narco tráfico internacional con dos nuevas aportaciones, que son la pertenencia a organización criminal y el empleo de buque o aeronave en el acto delictivo. La LO5/2010 de 22 de junio introdujo la primera cualificación especial ampliando el artículo 369. Con esta ampliación aparece el nuevo artículo 369 bis para el caso de que el supuesto autor del delito de tráfico de drogas perteneciere a una organización delictiva.

Este concepto de "Organización Criminal" se ha ido perfilando con las aportaciones de la Jurisprudencia del Tribunal Supremo, destacar por ello la STS 763/2007, 26 de septiembre, en línea con lo resuelto en las SSTS 1601/2005, 22 de diciembre, 808/2005, de 23 de junio y 1177/2003, 11 de septiembre, entre otras, la cual expone que:

\footnotetext{
${ }^{27}$ Acuerdo del Pleno de 19 de octubre de 2001 de la Sala Segunda del Tribunal Supremo
} 
“ya reiterábamos que el concepto de asociación u organización debe incluirse «cualquier red estructurada, sea cual fuere la forma de estructuración, que agrupe a una pluralidad de personas con una jerarquización y reparto de tareas o funciones entre ellas y que posea una vocación de permanencia en el tiempo». No cabe pasar por alto las expresiones que el Código incorpora al configurar esta hiperagravación o cualificación de segundo grado, refiriéndose a la «transitoriedad» de la asociación o a la «ocasionalidad» en la consecución de los fines perseguidos por ésta, lo que amplia en grado sumo las posibilidades subsuntivas de agrupaciones o asociaciones de dos o más personas que respondan a los criterios jurisprudenciales señalados. Una cuestión interpretativa más surge como consecuencia de la aparente desvinculación de esta figura cualificada del tipo básico al que se remite, por el hecho de relacionar la organización o asociación con la finalidad de difundir las sustancias o productos tóxicos o psicotrópicos, aunque debemos entender, desde una elemental interpretación lógica, que la conducta de difusión referida afecta y en definitiva constituye un modo de promoción, favorecimiento o facilitación del consumo ilegal de drogas."

Llegados a este punto se produce un claro choque entre "organización criminal" y la "codelincuencia", cuyas notas diferenciadoras han sido definidas por nuestro más alto Tribunal, aclarando que ${ }^{28}$ :

a) La forma jerárquica de la misma en la que unas personas, con mayor responsabilidad dan las órdenes que otras ejecutan. Las primeras normalmente están más apartadas del objeto del delito;

b) El reparto de papeles o funciones, lo que hace que un miembro con un cometido pueda ser reemplazado por otro sin que resulte afectado el grupo

c) Que posea vocación de estabilidad o permanencia en el tiempo, sin perjuicio de la evolución o acomodación de su estructura originaria a las circunstancias sobrevenidas en busca de una mayor eficacia en sus objetivos ilícitos y mayores obstaculizaciones o dificultades en el descubrimiento de la red criminal ${ }^{29}$.

\footnotetext{
${ }^{28}$ Sentencia del Tribunal Supremo 763/2007, 26 de septiembre de 2007

${ }^{29}$ Véanse en sentido similar las sentencias de esta sala de 8-2-93 (RJ 1993, 885), 10-11-94 (RJ 1994, 8808), 19-1-95 (RJ 1995, 569), 1-4-96, 13-10-97, 6-4-98, 29-2-2000, 3-11-2000, 26-3-2001, 16-7-2001 (RJ 2001, 6498), 20 y 29-11-2001 (RJ 2002, 1427), y 3-12-2002 (RJ 2003, 544),.
} 
Muy lejos de amedrentarse por esta nueva regulación, las bandas organizadas han ido metamorfoseándose para ir desencajando en el tipo expuesto anteriormente y poder evitar así la punidad de mayor pesaje. En esta lucha "conceptual" el legislador ha ido actualizándose para poder combatir el narcotráfico internacional adaptando el subtipo agravado de pertenencia a una organización a las nuevas realidades. De esta manera la jurisprudencia de nuestro Tribunal Supremo en el año 2009 matiza aún más el concepto de "banda criminal" y aglomera toda las marcas definitorias emitidas hasta entonces, determinando el nuevo concepto $\operatorname{como}^{30}$ :

"los autores hayan actuado dentro de una estructura caracterizada por un centro de decisiones y diversos niveles jerárquicos, con posibilidades de sustitución de unos a otros mediante una red de reemplazos que asegura la supervivencia del proyecto criminal con cierta independencia de las personas integrantes de la organización y que dificulten de manera extraordinaria la persecución de los delitos cometidos, aumentando al mismo tiempo, el daño posible causado. La existencia de la organización no depende del número de personas que la integren, aunque ello estará condicionado, naturalmente, por las características del plan delictivo; lo decisivo es, precisamente, esta posibilidad de desarrollo del plan delictivo de manera independiente de las personas individuales, pues ello es lo que permite hablar de una "empresa criminal" (SSTS de 19-1 y 26-6-95; 10- 2 y 25-5-97; y, 10-3-2000)".

La organización imprime mayor gravedad porque implica la concepción de la estructuración, orientación, funcionamiento del conjunto de las aportaciones; pero este elemento no se da en la adopción de papeles subordinados, definidos y coordinados por la organización. En el caso (como dice la STS de 20-7-2006, y recuerda la STS de 27-12009, núm. 16/2009), de los que sólo cooperan en un aspecto puntual y preparatorio, aunque sea importante, estos elementos no concurren. Es preciso considerar la analogía estructural que existe entre la organización delictiva y la empresa, no forman parte de la empresa los que sólo hacen aportaciones puntuales. La concurrencia de un conglomerado de personas estructurado para llevar a cabo de manera eficaz una actividad, sugiere, al menos en principio, una forma de organización, y, desde luego, no improvisada ni ocasional, dada la envergadura de la operación y la importancia de los medios empleados (STS de 18-9-2002, núm. 1481/2002). Ahora bien (Cfr. STS de 23-1-2003, núm. 57/2003), para evitar una desnaturalización de lo que se ha de ser entendido como

\footnotetext{
${ }^{30}$ Sentencia: $n^{\text {o }} 1154 / 2009$ de fecha $11 / 11 / 2009$
} 
organización -dado el carácter ocasional y transitoria que se requieren para la agravaciónesta Sala ha procurado buscar criterios que integren su contenido evitando que la misma pueda ser de aplicación tanto al famoso cártel que opera internacionalmente como grupo que opera en un barrio y se dedica al tráfico, pues ambos supuestos no presentan la misma antijuricidad. Por ello, se ha dicho por esta Sala, debe ser interpretada restrictivamente para guardar la debida proporcionalidad ante los hechos a los que se aplica. Ha de partirse de la acepción que proporciona el Diccionario de la Real Academia Organización significa "establecer o reformar una cosa, sujetado a reglas el número, orden, armonía y dependencia de las partes que lo componen o han de componerlo". La jurisprudencia en interpretación de esta agravación, ha distinguido entre participación plural de personas, encuadrable en el ámbito de la coautoría, y aquella otra que se integra en la modalidad agravada. En su virtud ha afirmado que la mera presencia de varias personas con decisión común en la ejecución de unos hechos típicos del delito contra la salud pública indica una pluralidad de personas que son autores o partícipes en el hecho delictivo, pero no tiene por qué suponer la aplicación de la agravación específica derivada de la organización. La pertenencia a una organización no puede confundirse con la situación de coautoría o coparticipación (SSTS de 30-6-92, 5-5-93, 21-5-97, 4-2-98, 28-11-01). La existencia de personas, aún coordinadas, no supone la existencia de una organización en cuanto aliud y plus, frente a la mera codelincuencia (Cfr. STS de 25-2-97, 4-2-98, 1-3-00)». (F. J. 18º)”

Llegados a este punto resulta necesario resumir lo asentado por la jurisprudencia como piezas definitorias de la agravante de "organización criminal", recogiéndose, por lo tanto:

a) la existencia de una estructura más o menos formalizada.

b) empleo de medios idóneos y adecuados para la consecución de los objetivos.

c) pluralidad de personas previamente concertadas.

d) distribución diferenciada de tareas o reparto de funciones.

e) existencia de coordinación.

f) cierta estabilidad temporal o vocación de continuidad. 
En referencia a la estabilidad para nuestro legislador es suficiente una "mínima permanencia" que permita distinguir estos supuestos de los de mera codelincuencia, abarcando incluso la organización constituida para una operación específica, siempre que se visualicen los otros puntos definitorios de este subtipo ${ }^{31}$.

Con la aparición de la Ley Orgánica 5/2010, de 22 de junio, se entra en un combate cuerpo a cuerpo con el narco tráfico internacional y a ello se le dedica, además de los artículos 368 y siguientes del Código Penal, un nuevo Capítulo VI en el Título XXII del Libro II, que bajo la rúbrica "De las organizaciones y grupos criminales", establece un concepto de organización criminal en el artículo 570 bis CP, exponiendo que ${ }^{32}$ :

“1. Quienes promovieren, constituyeren, organizaren, coordinaren o dirigieren una organización criminal serán castigados con la pena de prisión de cuatro a ocho años si aquélla tuviere por finalidad u objeto la comisión de delitos graves, y con la pena de prisión de tres a seis años en los demás casos; y quienes participaren activamente en la organización, formaren parte de ella o cooperaren económicamente o de cualquier otro modo con la misma serán castigados con las penas de prisión de dos a cinco años si tuviere como fin la comisión de delitos graves, y con la pena de prisión de uno a tres años en los demás casos.

A los efectos de este Código se entiende por organización criminal la agrupación formada por más de dos personas con carácter estable o por tiempo indefinido, que de manera concertada y coordinada se repartan diversas tareas o funciones con el fin de cometer delitos.

2. Las penas previstas en el número anterior se impondrán en su mitad superior cuando la organización:

\footnotetext{
${ }^{31}$ Véanse S.T.S. $\mathrm{n}^{\mathrm{o}} 1095$ de 16-07-2001; $\mathrm{n}^{\mathrm{o}} 2026$ de 28-11-2001; $\mathrm{n}^{\mathrm{o}} 1867$ de 07-11-2002; $\mathrm{n}^{\mathrm{o}} 620$ de 11-4$2002 ; n^{\circ} 57$ de 23-01-2003; no 108 de 05-05- 2003; no 759 de 23/05/2003; no 899 de 08/07/2004; n $^{\circ} 1167$ de 22-10-2004; $\mathrm{n}^{\circ} 164$ de 22-02-2006; n 278 de 10-03-2006; $\mathrm{n}^{\circ} 404$ de 03-04-2006; $\mathrm{n}^{\circ} 972$ de 28/09/2006; n 1009 de 18/10/2006; n 1163 de 16-11-2006; n 1286 de 30-11- 2006; n 426 de 16/05/2007; n 555 de 27-06-2007; n $^{\circ} 763$ de 26-09-2007; n $^{\circ} 780$ de $0310-2007 ; \mathrm{n}^{\circ} 31$ de 08-01-2008; $\mathrm{n}^{\circ}$ 171 de 17-04-2008; $\mathrm{n}^{\mathrm{o}} 233$ de 05-05- 2008; no 229 de 15-05-2008; no 413 de 30-06-2008; $\mathrm{n}^{\mathrm{o}} 511$ de 18 07-2008; $\mathrm{n}^{\circ} 531$ de 28-07-2008; $\mathrm{n}^{\circ} 727$ de 05-11-2008.

${ }^{32}$ Capítulo VI del Título XXII del Libro II, integrado por los artículos 570 bis, 570 ter y 570 quáter, introducido por el apartado centésimo cuadragésimo segundo y siguientes del artículo único de la L.O. 5/2010, de 22 de junio, por la que se modifica la L.O. 10/1995, de 23 de noviembre, del Código Penal («B.O.E.» 23 junio). Vigencia: 23 diciembre 2010
} 
a) esté formada por un elevado número de personas.

b) disponga de armas o instrumentos peligrosos.

c) disponga de medios tecnológicos avanzados de comunicación o transporte que por sus características resulten especialmente aptos para facilitar la ejecución de los delitos o la impunidad de los culpables.

Si concurrieran dos o más de dichas circunstancias se impondrán las penas superiores en grado.

3. Se impondrán en su mitad superior las penas respectivamente previstas en este artículo si los delitos fueren contra la vida o la integridad de las personas, la libertad, la libertad e indemnidad sexuales o la trata de seres humanos."

Con esta nueva redacción se estrecha más el lazo constrictor sobre el crimen organizando sintetizándose por la jurisprudencia que los elementos definitorios de la organización criminal $\operatorname{son}^{33}$ :

a) la agrupación de, al menos, tres personas para la comisión del delito

b) una actuación planeada, bien con carácter estable, bien por tiempo indefinido

c) el desarrollo de una tarea concertada y coordinada, con un reparto funcional de cometidos puestos al servicio del delito

Movidos por la gran aparición en los años 2013 y 2014 de estos casos de narcotráfico internacional el Gobierno español decidió en el año 2015 darle una vuelta más al entramado conceptual de organización criminal, asentando así el apartado 1 del artículo 570 ter, el cual defiende que ${ }^{34}$ :

"1. Quienes constituyeren, financiaren o integraren un grupo criminal serán castigados:

a) Si la finalidad del grupo es cometer delitos de los mencionados en el apartado 3 del artículo anterior, con la pena de dos a cuatro años de prisión si se trata de uno o más delitos graves y con la de uno a tres años de prisión si se trata de delitos menos graves.

\footnotetext{
${ }^{33}$ Sentencia del Tribunal Supremo 112/2012, 23 de febrero de 2012.

${ }^{34}$ Número 1 del artículo 570 bis redactado por el número doscientos cincuenta y tres del artículo único de la L.O. 1/2015, de 30 de marzo, por la que se modifica la L.O. 10/1995, de 23 de noviembre, del Código Penal («B.O.E.» 31 marzo). Vigencia: 1 julio 2015
} 
b) Con la pena de seis meses a dos años de prisión si la finalidad del grupo es cometer cualquier otro delito grave.

c) Con la pena de tres meses a un año de prisión cuando se trate de cometer uno o varios delitos menos graves no incluidos en el apartado a) o de la perpetración reiterada de delitos leves.

A los efectos de este Código se entiende por grupo criminal la unión de más de dos personas que, sin reunir alguna o algunas de las características de la organización criminal definida en el artículo anterior, tenga por finalidad o por objeto la perpetración concertada de delitos."

Este concepto de banda criminal va más allá de la mera organización creada y asentada en España, sino que agrupa a todo grupo criminal que lleve a cabo cualquier acto penalmente relevante en España, aunque se hayan constituido, estén asentados o desarrollen su actividad en el extranjero ${ }^{35}$.

Atendiendo a estos preceptos penales, pensamos que la banda punitiva recogida es mortal de necesidad sobre aquellas personas que osen cometer un delito de narcotráfico apoyados por otras personas, sin embargo, el legislador ha dejado una "salida de emergencia" que le permite a los jueces ser más benévolos, siendo esta el artículo 570 quáter, apartado 4, el cual recoge que:

“4. Los jueces o tribunales, razonándolo en la sentencia, podrán imponer al responsable de cualquiera de los delitos previstos en este Capítulo la pena inferior en uno o dos grados, siempre que el sujeto haya abandonado de forma voluntaria sus actividades delictivas y haya colaborado activamente con las autoridades o sus agentes, bien para obtener pruebas decisivas para la identificación o captura de otros responsables o para impedir la actuación o el desarrollo de las organizaciones o grupos a que haya pertenecido, bien para evitar la perpetración de un delito que se tratara de cometer en el seno o a través de dichas organizaciones o grupos.”

De esta manera el peso punitivo puede ser rebajado siempre y cuando el acusado de cometer un delito de muestre su arrepentimiento, abandone su actividad delictiva y apoyo de manera efectiva a las autoridades competentes.

\footnotetext{
${ }^{35}$ Apartado 3 del Artículo 570 quáter de la L.O. 10/1995, de 23 de noviembre, del Código Penal
} 